\title{
Energy intake and dietary patterns in childhood and throughout adulthood and mammographic density: results from a British prospective cohort
}

\author{
Gita D. Mishra • Isabel dos Santos Silva • \\ Sarah A. McNaughton • Alison Stephen • \\ Diana Kuh
}

Received: 19 April 2010/Accepted: 8 November 2010/Published online: 28 November 2010

(C) Springer Science+Business Media B.V. 2010

\begin{abstract}
Objectives To examine the role of energy intake and dietary patterns in childhood and throughout adulthood on subsequent mammographic density.

Methods Prospective data were available from a cohort of 1161 British women followed up since their birth in 1946. Dietary intakes at age 4 years were determined by 24-hour recalls and during adulthood, average food consumed at ages 36 and 43 years by 5-day food records. Dietary patterns were determined by factor analysis. Associations between energy intake, dietary patterns, and percent breast density were investigated using regression analysis.

Results During adulthood, energy intake was positively associated with percent breast density (adjusted regression
\end{abstract}

G. D. Mishra · D. Kuh

MRC Unit for Lifelong Health and Ageing, Department

of Epidemiology and Public Health, University College London,

London, UK

I. dos Santos Silva

Cancer Research UK Epidemiology and Genetics Group,

Department of Epidemiology and Population Health, London

School of Hygiene and Tropical Medicine, Bloomsbury, London, UK

\section{S. A. McNaughton}

Centre for Physical Activity and Nutrition Research,

Deakin University, Melbourne, VIC 3125, Australia

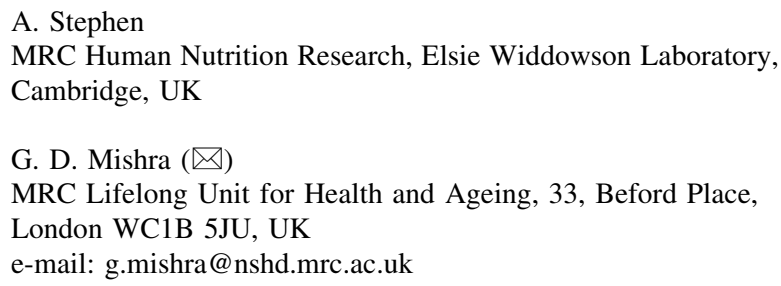

coefficient [per SD) $(95 \%$ CI): $0.12(0.01,0.23)]$. The effect of the high fat and sugar dietary pattern remained similar when adjusted for total energy intake $[0.06(-0.01$, $0.13)]$. There was no evidence of an associations for the patterns low fat, high fiber pattern 0.03 (-0.04, 0.11); the alcohol and fish $-0.02(-0.13,0.17)$; meat, potatoes, and vegetables $-0.03(-0.10,0.04)$. No association was found for dietary pattern at age 4 and percent breast density.

Conclusions This study supports the hypothesis that overall energy intake during middle life is a determinant of subsequent mammographic breast density measured 15 years later.

Keywords Diet · Fat · Energy - Sugar - Mammographic breast density

$\begin{array}{ll}\begin{array}{l}\text { Abbreviations } \\ \text { MRC NSHD }\end{array} & \begin{array}{l}\text { Medical Research Council National Survey } \\ \text { of Health and Development } \\ \text { National Health Service }\end{array} \\ \text { NHS } & \begin{array}{l}\text { Food frequency questionnaires } \\ \text { FFQ }\end{array} \\ \text { UK } & \text { United Kingdom } \\ \text { HT } & \text { Hormone therapy } \\ \text { BMI } & \text { Body mass index }\end{array}$

\section{Introduction}

Mammographic density has been shown to be a strong risk factor for breast cancer [1]. Previous epidemiological studies have investigated the relationship between individual nutrients or food groups and mammographic density with inconsistent findings. Some studies, but not others, 
$[2,3]$ have found a positive association with intake of total fat, polyunsaturated fats, polyunsaturated:saturated fat ratio, vitamins $\mathrm{C}$ and $\mathrm{E}$ [4-6]. The few studies that have published results on the intakes of protein, fiber, and carotenoid have also shown contradictory findings [2, 3, 6]. While the latest WCRF report concludes that there is 'convincing' evidence that alcohol intake is a risk factor for breast cancer in both pre- and post-menopausal women, [7] the result is less straightforward for mammographic density $[6,8-10]$.

Inconsistent findings across dietary studies that investigate the effect of single nutrients or food groups may be due to the failure of a single nutrient or food group to capture the dietary habit of an individual. A dietary patterns approach recognizes that foods are consumed in many combinations and that nutrient intakes are often highly correlated, with certain nutrients having interactive and synergistic effects. Furthermore, dietary patterns may be more stable over time than the consumption of individual foods [11-13]. A study of multiethnic cohort in Hawaii found a weak, inverse relationship between the pattern characterized by vegetables intake and mammographic density in Japanese women only [14]. Another recent study found a dietary pattern characterized by high-fat food choices was associated with increased risk of breast cancer incidence [15]. Results from the Minnesota Breast Cancer Family Study showed the inverse association between Mediterranean diet score and mammographic density was only seen in smokers [16]. All three studies assessed diet from food frequency questionnaires (FFQ) and relied on one single assessment of food intakes taken in midlife. Furthermore, while these studies have adjusted for total energy intake, the relationship between total energy intake and mammographic density were often not documented.

While the mechanism by which dietary patterns characterized by high-fat foods during adult life affects mammographic density is unclear, [14, 16] one possible pathway may be through the 'caloric restriction' hypothesis. Animal studies show that, during sustained caloric restrictions, cancer risks decreased proportionally to the amount of restrictions $[17,18]$. Of note that in a majority of the animal models evaluating energy restriction and cancer risk, the animals were subjected to lifelong dietary interventions [17]. Recent results from the Women's Health Initiative Dietary Modification Randomized Controlled Trial found that biomarker-calibrated energy intake was positively associated with breast cancer in post-menopausal women (hazard ratio: 1.23 ; 95\% CI: 1.06-1.41) [19].

Factors across the life course may increase risk of breast cancer [20-22] and thus dietary patterns at different ages may correlate with mammographic density. The Medical Research Council National Survey of Health and
Development (MRC NSHD), a population-based birth cohort study, [23] provides a unique opportunity to investigate whether dietary patterns and energy intake in childhood and throughout adulthood are related to women's breast density in midlife.

\section{Materials and methods}

The Medical Research Council National Survey of Health and Development is a British nationally representative sample of 2,815 men and 2,547 women followed since their birth in March 1946 [23]. Medical, sociodemographic, and lifestyle data have been collected at over 25 follow-ups by home visits, medical examinations, and postal questionnaires. Ethics approval was obtained from the North Thames Multicentre Research Ethics Committee.

\section{Dietary data}

At age 4 years, in 1950, a 24-hour maternal recall of all meals consumed was completed for $98 \%$ of cohort members [24]. Nutrient intakes were later calculated using period and age-specific food portion sizes and nutrient databases. At ages 36 and 43 years, all food and drink consumed both at home and away from home were recorded in 5-day food diaries using household measures and estimating portion sizes according to detailed guidance notes and photographs provided at the beginning of the diary. The foods and nutrient intakes were calculated using the in-house suites of programs based on McCance and Widdowson's The Composition of Foods and its Supplements [25]. Participants who provided food diaries at ages 36 and 43 years with four or more days completed were included in the analysis.

\section{Mammographic data}

In the United Kingdom, all women aged 50-64 years are invited for 3-yearly mammographic screening as part of the National Health Service (NHS) Breast Screening Programme. Copies of the mammograms with two views (craniocaudal and mediolateral oblique for each breast) taken when the women were closest to age 50, the prevalent screening round, were requested from the relevant centers. We successfully obtained copies of mammograms for 1,319 of the 1,471 women who gave consent $(90 \%$ tracing rate), the large majority [1,249 (95\%)] from NHS breast screening centers. Films were not obtained for the remaining women due to insufficient contact information for the hospitals/clinics (37 in UK, 12 overseas), logistic difficulties in certain centers $(n=57)$ and other problems ( $n=46)$ [26]. The mammograms were scanned using an 
Array 2905 laser digitiser with optical density range 0-4.0, 12 bit depth and pixel size of 75 microns.

Information for both mammographic density and food intakes was available for 1,161 (88\%) participants. Percent mammographic density, absolute areas of dense (parenchymal) and non-dense (fatty) tissues were measured on the left craniocaudal view $(n=1,014)$ or, if this was not available, on the left mediolateral oblique view $(n=147)$ using Cumulus, a computer-assisted threshold method [27].

Reproductive and other lifestyle factors

Age at menarche $(<12,12,13,14+$ years $)$ was reported by the participants' mothers when the girls were 15 years old or when this information was not available (for $9 \%$ of women) by the participants when they were 48 years old. Postal questionnaires were sent annually to women from ages 47 to 54 years to obtain information on menstrual characteristics and monthly change, hysterectomy and oopherectomy, and monthly hormone therapy (HT) use histories. These data were used to assess menopausal status at the time of mammography and, where appropriate, age at menopause. Women who reported no menstrual bleeding in the last 12 months were classified as post-menopause. Those with menstrual bleeding in the last 12 months, but not in the last 3 months, or with less regularity compared with the previous year were classified as peri-menopause. Those with menstrual bleeding in the last 3 months and with a regular or more regular menstrual bleeding than they had experienced in the previous year were classified as premenopause.

Height and weight were measured by a research nurse at age 53, and BMI was calculated as weight $/$ height $^{2}\left(\mathrm{~kg} / \mathrm{m}^{2}\right)$. Other factors, obtained at age 53 years, included in the study were smoking status and level of physical activity. Adult social class was based on a woman's own current or most recent occupation provided at age 43 .

\section{Statistical analysis}

The individual foods and beverages consumed at age 4 were summarized into 34 items. Due to the large variety of foods and beverages consumed during adulthood, 70 categories of related foods and drinks groupings were formed, for ages 36 and 43 [12]. Dietary patterns were determined by factor analysis, conducted separately for ages 4,36 , and 43 , using the method of principal components and varimax rotation. The number of dietary patterns identified was based on eigenvalues $>1.25$, identification of a break point in the screen plot and interpretability [28]. Items were considered to load on a factor if they had a correlation $\geq 10.30 \mid$ with that factor [28]. Inter-item reliability for each factor was assessed by Cronbach's alpha coefficients. Since the dietary patterns identified at ages 36 and 43 were similar in relation to the number of factors identified and the foods that loaded highly, factor analysis was rerun on the average consumption of food items between the two adult ages to represent habitual dietary patterns during adulthood. Dietary pattern scores were calculated by taking the product of the weight of each food item consumed and the standardized factor scores and summing this value over all the food items. All foods and beverages items contributed to the calculation of dietary pattern scores. Thirds of dietary pattern scores were used in the analysis.

Percent breast density was square root transformed and then standardized. Multivariable linear regression models were used to investigate the relationship between percent breast density (and the absolute area of dense and nondense breast tissue) and the main exposures of interest, namely dietary patterns in thirds (at ages 4, 36, and 43), while adjusting for mammographic view (craniocaudal, mediolateral oblique), age at mammogram (continuous), body mass index (BMI) at age 53 (continuous), age at menarche $(<12,12,13,14+$ years $)$, menopausal status at the time of mammography (pre-, peri-, post-, hysterectomy), HT use (current or ever), parity $(0,1,2,3,4+)$, smoking status (current smoker, non-smoker), level of physical activity (nil, moderate, high), and social class during adult life (non-manual, manual) (Model 1). Total energy intake was included in the final model in order to assess if it attenuated the relationships between the dietary patterns and mammographic density (Model 2). Linear trends across thirds of dietary pattern scores were also calculated. The multivariable analyses were performed on complete case data. Statistical analysis was conducted with SAS Version 9.1 [29], and differences with $p$-values $<0.05$ were considered to be significant.

\section{Results}

Table 1 presents the reproductive and lifestyle characteristics of the 1,161 participants with data on mammographic density. The mean age at mammography was 51.5 years. Results from factor analyses revealed three dietary patterns at age 4 years and four dietary patterns during adulthood. Tables 2 and 3 present the factor loading for these dietary patterns. A positive loading indicates a positive association between the item and the dietary pattern. At both stages in life, the identified dietary patterns explained approximately $15 \%$ of the variance in the consumption of all the food items.

Based on the type of food items consumed with factor loadings $\geq 10.30 \mid$, dietary patterns at age 4 were labeled as breads and fats, fried potatoes and fish, and milk, fruit and biscuits (Table 2). Four dietary patterns were identified during adulthood. Patterns emerging among the women 
Table 1 Characteristics of the participants with data on mammographic density $(n=1,161)$
${ }^{a} n$ varies due to missing data

\begin{tabular}{|c|c|}
\hline & $\begin{array}{l}\text { Mean (SD), median } \\
\text { or percentage }(n)\end{array}$ \\
\hline Percent mammographic density & $25(18.1), 21.9$ \\
\hline BMI at age $53\left(\mathrm{~kg} / \mathrm{m}^{2}\right)(n=1,124)^{\mathrm{a}}$ & $27.6(5.48), 26.5$ \\
\hline Age at mammography in years $(n=1,130)^{\mathrm{a}}$ & $51.5(1.1), 51.5$ \\
\hline \multicolumn{2}{|l|}{ Age at menarche } \\
\hline$<12$ & $13 \%(151)$ \\
\hline 12 & $22 \%(255)$ \\
\hline 13 & $28 \%(325)$ \\
\hline $14+$ & $16 \%(186)$ \\
\hline Missing & $22 \%(244)$ \\
\hline \multicolumn{2}{|l|}{ Menopausal status at the time of mammography } \\
\hline Pre-menopause & $17 \%(197)$ \\
\hline Peri-menopause & $17 \%(197)$ \\
\hline Post-menopause & $24 \%(279)$ \\
\hline Hysterectomy & $19 \%(221)$ \\
\hline HRT/oral contraceptive pill & $18 \%(209)$ \\
\hline Unknown & $5 \%(58)$ \\
\hline \multicolumn{2}{|l|}{ History of hormone therapy use } \\
\hline Never & $54 \%(627)$ \\
\hline Ever & $46 \%(534)$ \\
\hline \multicolumn{2}{|l|}{ Parity } \\
\hline 0 & $12 \%(139)$ \\
\hline 1 & $11 \%(128)$ \\
\hline 2 & $45 \%(512)$ \\
\hline 3 & $22 \%(255)$ \\
\hline $4+$ & $8 \%(93)$ \\
\hline Missing & $2 \%(23)$ \\
\hline \multicolumn{2}{|l|}{ Smoking status at age 53} \\
\hline Current smoker & $21 \%(244)$ \\
\hline Non-smoker & $77 \%(894)$ \\
\hline Missing & $2 \%(23)$ \\
\hline \multicolumn{2}{|l|}{ Level of physical activity at age 53} \\
\hline Nil & $48 \%(557)$ \\
\hline Moderate & $16 \%(186)$ \\
\hline High & $34 \%(395)$ \\
\hline Missing & $2 \%(23)$ \\
\hline
\end{tabular}

The effect of the high fat and sugar pattern on dense were labeled 'low fat, high fiber', 'alcohol and fish' (which includes items indicative of a Mediterranean style diet), 'high fat and sugar', 'meat, potatoes, and vegetables' (Table 3).

There was no evidence of an association between dietary patterns or energy intake at age 4 and percent mammographic density (Table 4). During adulthood, a higher energy intake and increased consumption of items in the alcohol and fish pattern and high fat and sugar pattern were associated with higher percent mammographic density. (Table 5; Model 1). However, in the mutually adjusted model, only energy intake remained positively associated with mammographic density (Table 5; Model 2). tissue area was greatly attenuated when total energy intake was taken into account. Higher energy intake was significantly associated with a larger area of dense tissues (Table 6; Model 2). Neither dietary patterns nor energy consumption was associated with area of non-dense tissues.

\section{Discussion}

This analysis identified that total energy intake rather than specific dietary patterns during adulthood was associated with percent breast density. The weak effect of a high fat 
Table 2 Factor loadings and cumulative percentage of variation estimated from women at age 4 years based on 24-hour recall $(n=1,088)$

a Only absolute loading greater than 0.3 shown. All 34 food items were used in the calculation of factor scores

b Cumulative percentage of variation: The total percentage variance in the consumption of all the food items explained by the index factor and all the previous factors, e.g., factors 1 and 2 explained $11 \%$ of the total variance in total food consumption

\begin{tabular}{|c|c|c|}
\hline & $\begin{array}{l}\text { Mean daily consumption } \\
\text { (g/day) SD, median }\end{array}$ & $\begin{array}{l}\text { Factor } \\
\text { loading }^{\text {a }}\end{array}$ \\
\hline \multicolumn{3}{|l|}{ Factor 1 (bread and fats) $(6 \%)^{\mathrm{b}}$} \\
\hline Breads & $121(47), 140$ & 0.74 \\
\hline Fats, all type & $9(5), 7$ & 0.70 \\
\hline Coffee/tea & $188(201)$ & 0.33 \\
\hline Soups & $9(37)$ & -0.37 \\
\hline \multicolumn{3}{|l|}{ Factor 2 (fried potatoes and fish) $(11 \%)^{\mathrm{b}}$} \\
\hline Fried potatoes, chips & $17(45), 0$ & 0.56 \\
\hline Fish, all & $7(23), 0$ & 0.52 \\
\hline Potato and vegetables product, cooked & $60(42), 80$ & -0.60 \\
\hline Desserts, all & $95(90), 100$ & -0.32 \\
\hline \multicolumn{3}{|l|}{ Factor 3 (milk, fruit, and biscuits) $(16 \%)^{\mathrm{b}}$} \\
\hline Whole milk & $311(160), 300$ & 0.52 \\
\hline All fruit (except apples and pears) & $30(46), 0$ & 0.38 \\
\hline Biscuits, all & $4(8), 0$ & 0.31 \\
\hline Sweets, chocolates, sugars, preserves & 20 (19), 11 & -0.41 \\
\hline Porridge & $10(33), 0$ & -0.44 \\
\hline Coffee/tea & 188 (201), 220 & -0.52 \\
\hline
\end{tabular}

and sugar pattern (characterized by high intakes of sweet biscuits and cakes, whole milk, confectionary, sweet puddings, and butter) on mammographic density remained when total energy intake was taken into account. There was no evidence of an association between dietary patterns at age 4 or energy intake and percent breast density. In terms of dense/non-dense areas of the breast, the effect of adult dietary pattern of high fat and sugar pattern was slightly attenuated when total energy intake was taken into account. A positive association was found between total energy intake and area of dense tissue.

The lack of evidence of a relationship between adult dietary patterns and mammographic densities in our study was consistent with results published recently showing no significant association between the 'fat and meat' pattern and mammographic density in a large multiethnic Hawaiian cohort [14]. In the present study, we did not find any associations with dietary patterns characterized by the high consumption of vegetables. This agrees with the findings from the Hawaiian cohort among Caucasian women [14]. However, in the Minnesota Breast Cancer Family study, no strong evidence for associations of dietary patterns with breast density was found, but a weak inverse relationship was identified for the fruit-vegetable-cereal and saladsauce-pasta/grain dietary patterns [16].

As mammographic density is a surrogate marker for breast cancer risk, it is informative to compare the findings of dietary patterns with respect to breast cancer cases. Positive associations were also observed in the European Prospective Investigation into Cancer and Nutrition-Potsdam study where a dietary pattern characterized by high-fat food choices was associated with the incident of invasive breast cancer [15]. In the Women's Health Initiative Dietary Modification Randomized Controlled Trial, a weak inverse relationship was found between a low-fat diet and invasive breast cancer in post-menopausal women (hazard ratio: 0.91 ; 95\% CI: 0.83-1.01) [30]. Our data provide weak evidence of a positive association between the high fat and sugar pattern and mammographic density.

While the role of energy intake on mammographic density is unclear, there is substantial evidence for increased breast cancer risk with high energy intake [31, 32]. Numerous biological mechanisms have been postulated to explain how increased energy intake promotes breast cancer risks including through: (1) the alterations in the production of ovarian steroid hormones, particularly estrodial, which is believed to increase breast cancer risk [33]; (2) the changes in the availability of insulin growth factor-1, which in turn, promotes tumor development by increasing cell proliferation [34]; (3) the increase DNA replication rate reduces the rate of apoptosis, thus increasing tissue susceptibility to damaging carcinogens [35]. However, research on the women exposed to the 1944-1945 Dutch famine, a relatively short, severe famine during in World War II, found an increased breast cancer risk $[36,37]$. The authors concluded that being exposed to "normal" diet after a period of short and transient period of restriction could be detrimental [36, 37]. The high-energy associations with percent density reflected mainly positive associations with the dense area. From our previous work where we have shown that dietary patterns tracks in adulthood, [12] it may be possible that sustained high 
Table 3 Factor loadings and cumulative percentage of variation estimated from women during adulthood ${ }^{\mathrm{b}}$ based on 5-day food diary $(n=954)$ a Only absolute loading greater than 0.3 shown. All 70 food items were used in the calculation of factor scores

${ }^{\mathrm{b}}$ Factor analysis was carried out on mean dietary intake at age 36 and 43

c Cumulative percentage of variation: The total percentage variance in the consumption of all the food items explained by the index factor and all the previous factors, e.g., factors 1 and 2 explained $9 \%$ of the total variance in total food consumption

\begin{tabular}{lll}
\hline Dietary patterns & $\begin{array}{l}\text { Mean daily consumption } \\
(\mathrm{g} / \text { day) SD, median }\end{array}$ & $\begin{array}{l}\text { Factor } \\
\text { loading }^{\mathrm{a}}\end{array}$ \\
\hline
\end{tabular}

Factor 1 (low fat, high fiber) $(6 \%)^{\mathrm{c}}$

Other fruit

134 (110), 114

0.59

Skimmed milk

93 (114), 59

0.51

Yoghurt

Wholemeal breads

52 (111), 0

0.51

37 (41), 30

0.46

Citrus fruit

Breakfast cereal (medium-high fiber)

38 (58), 0

0.40

13 (15), 0

0.39

Breakfast cereals, muesli

Savoury biscuits

Low-fat cheese

Low-fat spreads

White bread

Factor 2 (alcohol and fish) $(10 \%)^{\mathrm{c}}$

White wine

Vegetables, mixed

$5.0(12), 0$

0.39

10 (11), 7

0.37

9 (23), 0

0.35

3 (6), 0

0.30

73 (40), 74

$-0.34$

83 (123), $0 \quad 0.58$

109 (79), $95 \quad 0.56$

Red wine

Olive oil

Shellfish

Fruit juice, unsweetened

Spirits

Fortified wine

Rice

Other leafy vegetables

Broccoli

Oily fish

Factor 3 (high fat and sugar) $(13 \%)^{\mathrm{c}}$

Whole milk

$31(78), 0 \quad 0.54$

$0.2(2), 0 \quad 0.39$

9 (26), $0 \quad 0.36$

$70(84), 55 \quad 0.35$

$13(25), 0 \quad 0.35$

15 (29), $0 \quad 0.34$

$38(59), 0 \quad 0.31$

$21(22), 16 \quad 0.31$

$8(21), 0 \quad 0.31$

29 (46), $0 \quad 0.31$

140 (103), $121 \quad 0.60$

$\begin{array}{lll}\text { Sweet biscuits and cakes } & 97(64), 93 & 0.59\end{array}$

Confectionary

Sweet puddings

Butter

Chocolate

$33(28), 28$

$157(120), 138$

$10(10), 9 \quad 0.39$

$23(32), 11 \quad 0.38$

Factor 4 (meat, potatoes and vegetables) $(16 \%)^{\mathrm{c}}$

Potatoes (excluding chips and crisps)

$154(75), 152 \quad 0.42$

Red meat

0.43

Peas, green beans

Other fats and vegetable oils

Sauces, dressings

Animal fat

Cruciferous vegetables

Potatoes, fried

Carrots

Legumes, baked beans

120 (78), 114

0.41

48 (37), 43

0.40

10 (10), 9

$\begin{array}{ll}48(34), 45 & 0.38 \\ 2(4), 0 & 0.36\end{array}$

$56(53), 45 \quad 0.36$

$72(86), 65 \quad 0.35$

$29(28), 26 \quad 0.33$

$28(42), 0 \quad 0.32$

Tomatoes energy diet may lead to high mammographic density through one of the biological mechanism mentioned above.

To our knowledge, no studies have investigated the role of dietary patterns during adult life using repeat measures of dietary intakes (seven years apart) with mammographic density in midlife. The prospective nature with dietary data collected prior to mammographic screening, sample size, length of follow-up, and wide range of potential risk factors 
Table 4 Adjusted regression coefficient (95\% confidence intervals) for standardized square root of percent breast density by dietary patterns at age 4 years $(n=792)$

\begin{tabular}{lrr}
\hline & Model $1^{\mathrm{a}}$ & Model $2^{\mathrm{b}}$ \\
\hline Dietary patterns (per SD) & & \\
Bread and fats & $0(-0.06,0.07)$ & $-0.004(-0.08,0.07)$ \\
Fried potatoes and fish & $-0.05(-0.12,0.01)$ & $-0.05(-0.12,0.01)$ \\
Milk, fruit, and biscuits & $-0.013(-0.08,0.05)$ & $-0.01(-0.08,0.05)$ \\
Total energy (J/d) (per SD) & $-0.007(-0.07,0.05)$ & $0(-0.08,0.07)$ \\
\hline
\end{tabular}

${ }^{a}$ Model 1: Adjusted for mammographic view, age at mammogram, BMI at age 53, age at menarche, menopausal status at the time of mammography, HT use, parity, smoking status, physical activity, social class, and the other three dietary patterns (excluding energy intake)

b Model 2: Additionally adjusted for energy intake

Table 5 Adjusted regression coefficient (95\% confidence intervals) for standardized square root of percent breast density by dietary patterns during adult life $(n=700)$

\begin{tabular}{lrr}
\hline & Model $1^{\mathrm{a}}$ & Model $2^{\mathrm{b}}$ \\
\hline Dietary patterns (per SD) & & $0.03(-0.04,0.11)$ \\
Low fat, high fiber & $0.06(-0.01,0.12)$ & $-0.02(-0.13,0.17)$ \\
Alcohol and fish & $0.08(0.01,0.15)$ & $0.06(-0.01,0.13)$ \\
High fat and sugar & $0.07(0.00,0.14)$ & $-0.03(-0.10,0.04)$ \\
Meat, potatoes and vegetables & $-0.01(-0.08,0.06)$ & $0.12(0.01,0.23)$ \\
Total energy intake (J/d) (per SD) & $0.11(0.05,0.18)$ & 0.12 \\
\hline
\end{tabular}

${ }^{a}$ Model 1: Adjusted for mammographic view, age at mammogram, BMI at age 53, age at menarche, menopausal status at the time of mammography, HT use, parity, smoking status, physical activity, social class, and the other three dietary patterns (excluding energy intake)

b Model 2: Additionally adjusted for energy intake

Table 6 Adjusted regression coefficient (95\% confidence intervals) for absolute dense and non-dense tissue areas by dietary patterns during adult life $(n=700)$

\begin{tabular}{|c|c|c|c|c|}
\hline \multirow[t]{2}{*}{ Dietary patterns (per SD) } & \multicolumn{2}{|c|}{ Area of dense tissues } & \multicolumn{2}{|l|}{ Area of non-dense tissues } \\
\hline & Model $1^{\mathrm{a}}$ & Model $2^{\mathrm{b}}$ & Model $1^{\mathrm{a}}$ & Model $2^{\mathrm{b}}$ \\
\hline Low fat, high fiber & $0.03(-0.05,0.10)$ & $-0.002(-0.08,0.08)$ & $-0.01(-0.02,-0.003)$ & $-0.01(-0.02,0.00)$ \\
\hline Alcohol and fish & $0.03(-0.05,0.10)$ & $-0.07(-0.20,0.05)$ & $-0.02(-0.03,-0.01)$ & $-0.01(-0.03,0.01)$ \\
\hline High fat and sugar & $0.09(0.01,0.17)$ & $0.07(-0.01,0.15)$ & $-0.01(-0.02,0.01)$ & $-0.004(-0.014,0.01)$ \\
\hline Meat, potatoes and vegetables & $0.01(-0.06,0.09)$ & $-0.01(-0.08,0.07)$ & $0.01(-0.001,0.016)$ & $0.01(-0.003,0.02)$ \\
\hline Total energy intake (J/D) (per SD) & $0.07(-0.01,0.14)$ & $0.12(0.00,0.25)$ & $-0.02(-0.03,-0.01)$ & $-0.01(-0.03,0.004)$ \\
\hline
\end{tabular}

${ }^{a}$ Model 1: Adjusted for mammographic view, age at mammogram, BMI at age 53, age at menarche, menopausal status at the time of mammography, HT use, parity, smoking status, physical activity, social class, and the other three dietary patterns (excluding energy intake)

b Model 2: Additionally adjusted for energy intake

are major strengths of this study. The MRC NSHD is one of the few cohorts with measures of diet collected in childhood and with repeated measures throughout adult life. Dietary intakes in adulthood were based on diaries rather than FFQ, which provided detailed data on the variety of foods consumed. The single 24-h recalls, used at the age of 4 years, are not generally considered to be reflective of usual intake and not the preferred dietary assessment method for associations with health or disease outcomes. However, the diets in the 1950s were much less variable than in more recent times, and a dietary pattern shown for one day is likely to be repeated throughout the week, particularly major foods such as fruits and vegetables, meat, and milk [38].

We have already shown that these dietary data are robust enough for epidemiologic studies, when used either to compare group means or with rank subjects according to the levels of food consumption [39]. Period-specific food composition databases were used to calculate intakes allowing for real changes in food composition over time to be incorporated into the exposure measurement. Percent density readings were highly repeatable (90 films were 
independently and blindly re-read, giving an intra-class correlation coefficient of $0.91,95 \%$ CI: $0.89,0.93$ ), and relationships with the established determinants of density (e.g., BMI, menopausal status, and hormone therapy use) were observed, giving weight to the validity of the outcome data.

This study supports the hypothesis that high energy intake, rather than any specific dietary patterns, established in mid-thirties is associated with mammographic density in later life.

\section{Conclusions}

Our study supports the hypothesis that high energy intake during the mid-thirties and early forties is associated with mammographic density measured 15 years later. Further research is warranted on the repeatability of these findings and to investigate potential underlying mechanisms.

Acknowledgments This work was funded by the Breast Cancer Campaign UK, the World Cancer Research Fund International and the Medical Research Council.

Conflict of interest The authors declare that they have no competing interests.

\section{References}

1. McCormack VA, dos SS I (2006) Breast density and parenchymal patterns as markers of breast cancer risk: a meta-analysis. Cancer Epidemiol Biomarkers Prev 15:1159-1169

2. Brisson J, Verreault R, Morrison AS, Tennina S, Meyer F (1989) Diet, mammographic features of breast tissue and breast cancer risk. Am J Epidemiol 130:14-24

3. Jakes RW, Duffy SW, Ng FC et al (2002) Mammographic parenchymal patterns and self-reported soy intake in Singapore Chinese women. Cancer Epidemiol Biomarkers Prev 11: 608-613

4. Boyd NF, Greenberg C, Lockwood G et al (1997) Effects at two years of a low-fat, high-carbohydrate diet on radiologic features of the breast: results from a randomized trial: For the Canadian diet and breast cancer prevention study group. J Natl Cancer Inst 89:488-496

5. Knight JA, Martin LJ, Greenberg CV et al (1999) Macronutrient intake and change in mammographic density at menopause: results from a randomized trial. Cancer Epidemiol Biomarkers Prev 8:123-128

6. Vachon CM, Kushi LH, Cerhan JR, Kuni CC, Sellers TA (2000) Association of diet and mammographic breast density in the Minnesota breast cancer family cohort. Cancer Epidemiol Biomarkers Prev 9:151-160

7. World Cancer Research (2007) Food, nutrition, physical activity, and the prevention of cancer: a global perspective. AICR, Washington, DC

8. Berube S, Diorio C, Verhoek-Oftedahl W, Brisson J (2004) Vitamin D, calcium, and mammographic breast densities. Cancer Epidemiol Biomarkers Prev 13:1466-1472
9. Maskarinec G, Takata Y, Pagano I, Lurie G, Wilkens LR, Kolonel LN (2006) Alcohol consumption and mammographic density in a multiethnic population. Int J Cancer 118:2579-2583

10. Vachon CM, Sellers TA, Janney CA et al (2005) Alcohol intake in adolescence and mammographic density. Int $\mathrm{J}$ Cancer 117:837-841

11. Borland SE, Robinson SM, Crozier SR, Inskip HM (2008) Stability of dietary patterns in young women over a 2-year period. Eur J Clin Nutr 62:119-126

12. Mishra GD, McNaughton SA, Bramwell GD, Wadsworth ME (2006) Longitudinal changes in dietary patterns during adult life. Br J Nutr 96:735-744

13. Newby PK, Weismayer C, Akesson A, Tucker KL, Wolk A (2006) Long-term stability of food patterns identified by use of factor analysis among Swedish women. J Nutr 136:626-633

14. Takata Y, Maskarinec G, Park SY, Murphy SP, Wilkens LR, Kolonel LN (2007) Mammographic density and dietary patterns: the multiethnic cohort. Eur J Cancer Prev 16:409-414

15. Schulz M, Hoffmann K, Weikert C, Nothlings U, Schulze MB, Boeing $\mathrm{H}$ (2008) Identification of a dietary pattern characterized by high-fat food choices associated with increased risk of breast cancer: the European prospective investigation into cancer and nutrition (EPIC)-potsdam study. Br J Nutr 100:942-946

16. Tseng M, Vierkant RA, Kushi LH, Sellers TA, Vachon CM (2008) Dietary patterns and breast density in the Minnesota breast cancer family study. Cancer Causes Control 19(5):481-489

17. Kritchevsky D (1997) Caloric restriction and experimental mammary carcinogenesis. Breast Cancer Res Treat 46:161-167

18. Dirx MJ, Zeegers MP, Dagnelie PC, van den BT, van den Brandt PA (2003) Energy restriction and the risk of spontaneous mammary tumors in mice: a meta-analysis. Int J Cancer 106:766-770

19. Prentice RL, Shaw PA, Bingham SA et al (2009) Biomarkercalibrated energy and protein consumption and increased cancer risk among postmenopausal women. Am J Epidemiol 169: 977-989

20. dos Santos Silva I, De Stavola B (2002) Breast cancer aetiology: where do we go from here? In: Kuh D, Hardy R (eds) A life course approach to women's health. Oxford University Press, Oxford, pp 44-63

21. dos Santos Silva I, De Stavola BL, Hardy RJ, Kuh DJ, McCormack VA, Wadsworth ME (2004) Is the association of birth weight with premenopausal breast cancer risk mediated through childhood growth? Br J Cancer 91:519-524

22. Sellers TA, Vachon CM, Pankratz VS et al (2007) Association of childhood and adolescent anthropometric factors, physical activity, and diet with adult mammographic breast density. Am J Epidemiol 166:456-464

23. Wadsworth M, Kuh D, Richards M, Hardy R (2006) Cohort profile: the 1946 national birth cohort (MRC national survey of health and development). Int J Epidemiol 35:49-54

24. Prynne CJ, Paul AA, Price GM, Day KC, Hilder WS, Wadsworth ME (1999) Food and nutrient intake of a national sample of 4year-old children in 1950: comparison with the 1990s. Public Health Nutr 2:537-547

25. Prynne CJ, Paul AA, Mishra GD, Greenberg DC, Wadsworth ME (2005) Changes in intake of key nutrients over 17 years during adult life of a British birth cohort. Br J Nutr 94:368-376

26. McCormack VA, dos SS I, De Stavola BL et al (2003) Lifecourse body size and perimenopausal mammographic parenchymal patterns in the MRC 1946 British birth cohort. Br J Cancer 89:852-859

27. Byng JW, Boyd NF, Fishell E, Jong RA, Yaffe MJ (1994) The quantitative analysis of mammographic densities. Phys Med Biol 39:1629-1638

28. Kline P (1994) An easy guide to factor analysis. Routledge, London 
29. SAS Institute (1999) SAS/STAT users guide. SAS Institute Inc, Cary, NC

30. Tinker LF, Bonds DE, Margolis KL et al (2008) Low-fat dietary pattern and risk of treated diabetes mellitus in postmenopausal women: the women's health initiative randomized controlled dietary modification trial. Arch Intern Med 168:1500-1511

31. Silvera SA, Jain M, Howe GR, Miller AB, Rohan TE (2006) Energy balance and breast cancer risk: a prospective cohort study. Breast Cancer Res Treat 97:97-106

32. Malin A, Matthews CE, Shu XO et al (2005) Energy balance and breast cancer risk. Cancer Epidemiol Biomarkers Prev 14: 1496-1501

33. Key TJ, Verkasalo PK, Banks E (2001) Epidemiology of breast cancer. Lancet Oncol 2:133-140

34. Fair AM, Montgomery K (2009) Energy balance, physical activity, and cancer risk. Methods Mol Biol 472:57-88

35. Hursting SD, Lavigne JA, Berrigan D, Perkins SN, Barrett JC (2003) Calorie restriction, aging, and cancer prevention: mechanisms of action and applicability to humans. Annu Rev Med 54:131-152

36. Elias SG, Peeters PH, Grobbee DE, van Noord PA (2004) Breast cancer risk after caloric restriction during the 1944-1945 Dutch famine. J Natl Cancer Inst 96:539-546

37. Elias SG, Peeters PH, Grobbee DE, van Noord PA (2007) Transient caloric restriction and cancer risk (The Netherlands). Cancer Causes Control 18:1-5

38. Prynne CJ, Paul AA, Mishra GD, Hardy RJ, Bolton-Smith C, Wadsworth ME (2002) Sociodemographic inequalities in the diet of young children in the 1946 British birth cohort. Public Health Nutr 5:733-745

39. Mishra GD, Malik NS, Paul AA, Wadsworth ME, Bolton-Smith C (2003) Childhood and adult dietary vitamin E intake and cardiovascular risk factors in mid-life in the 1946 British birth cohort. Eur J Clin Nutr 57:1418-1425 